\title{
Knowledge sharing through social media: Investigating trends and technologies in a global marketing and advertising research company
}

\author{
Authors: \\ Dina Adamovic ${ }^{1}$ \\ Andrea Potgieter ${ }^{1}$ \\ Martie Mearns ${ }^{1}$

\section{Affiliations:} \\ ${ }^{1}$ Department of \\ Information and Knowledge \\ Management, University of \\ Johannesburg, South Africa \\ Correspondence to: \\ Andrea Potgieter \\ Email: \\ apotgieter@uj.ac.za \\ Postal address: \\ PO Box 524, Auckland Park \\ 2006, South Africa \\ Dates: \\ Received: 17 Jan. 2012 \\ Accepted: 25 May 2012 \\ Published: 19 July 2012 \\ Republished: 26 July 2012 \\ How to cite this article: \\ Adamovic, D. \& Potgieter, \\ A. \& Mearns, M., 2012, \\ Knowledge sharing through \\ social media: Investigating \\ trends and technologies \\ in a global marketing \\ and advertising research \\ company, SA Journal of \\ Information Management \\ 14(1), Art. \#514, 7 pages. \\ http://dx.doi.org/10.4102/ \\ sajim.v14i1.514

\section{Note:} \\ This article is republished \\ with the correct author \\ order.
}

Background: The purpose of this study was to investigate social media technology trends in Nielsen - a global information and measurement company - and to establish how these technologies can help the company to create a knowledge-sharing culture.

Objective: The objective of this study was to investigate trends in knowledge-sharing technologies in Nielsen.

Method: The researchers distributed semi-structured questionnaires to a sample of employees in Nielsen's Television Audience Measurement Department. They also conducted interviews with specific employees in this department to gain a better understanding of employees' attitudes toward, and perceptions of, the use of social media tools for creating a knowledgesharing culture at Nielsen. The researchers validated the data to see whether it could support the research and used triangulation to create a holistic view of the data they received from the questionnaires.

Results: The findings of the study revealed that respondents had a positive attitude to sharing knowledge with one another through using social media tools. However, some respondents thought that technology, in general, was 'the tree of good and evil'. The survey findings showed that Nielsen did have social media tools. However, not all employees were aware of these tools or were willing to use the tools to share knowledge. This study highlighted the possible advantages of the social media for sharing knowledge and how Nielsen could use the tools more widely.

Conclusion: In order for a knowledge sharing culture to thrive at Nielsen, its employees need to engage more with social media tools in their business practices.

\section{Introduction}

Nielsen - a global information and measurement company - provides clients with an understanding of consumer needs that it bases on consumer behaviour. Nielsen delivers critical media and marketing information, analytics and industry expertise about what consumers watch (consumer interaction with television, online and mobile devices) and what consumers locally and globally. In companies like Nielsen, sharing knowledge between employees is vital.

In practice, knowledge sharing is evident when employees share their tacit knowledge with one another. If communal sharing of knowledge is commonplace within a company, a knowledgesharing culture will manifest and this culture allows employees to exchange valuable information with each another. Social media technologies can assist the process of sharing knowledge in organisations because it allows easy and instant communication. The unique features of social media technologies, which are digital in nature, enable companies like Nielsen to determine the best strategy to increase knowledge sharing with other companies. However, this research aimed to establish the degree to which Nielsen employees have embraced social media technologies in order to share knowledge within the organisation.

Foss, Husted and Michailova (2010) mention several reasons for focusing on sharing knowledge in organisations:

- 'knowledge sharing is designed to transform individual knowledge into organisational knowledge'

- modern organisational culture is synonymous with knowledge sharing processes

- organisations that share knowledge 'may lead to improved innovation capacity, ... and therefore, to sustained competitive advantage'. 
Social media is a dynamic field that Nielsen can use to manage its knowledge sharing. '[Social Media] is used as a communication tool where employees within the organisation will be able to engage in knowledge sharing' (Jones, Temperley \& Lima 2009).

The researchers conducted this study on a team of employees in the Nielsen Television Audience Measurement Department. They analysed gaps and trends in the organisation in order to evaluate knowledge sharing within Nielsen. They conducted qualitative research to perform an in-depth analysis of what employees' thoughts are about social media tools and sharing knowledge.

Nielsen's attempt to use the social media specifically for sharing knowledge between employees makes sense. Gaffoor and Cloete (2010) support the idea that technology aids knowledge sharing:

The age of technology where knowledge and information serve as key strategic tools in the organisational context, creates the opportunity for organisations to adopt the role of knowledgebased organisations that thrive on the competence of knowledge workers. (n.p.)

Whilst Nielsen aims to create a knowledge-sharing environment through using social media tools, for its employees to share knowledge optimally it is important for the company to facilitate and cultivate engagement between employees - no matter how. Employees are important assets in an organisation as their intellectual capital (IC) is a resource that is embedded in their actions and capabilities (Longo \& Mura 2011). What employees do with their IC is extremely important because 'every employee has a sphere of influence along with their individual knowledge, and this is where a knowledge sharing culture can begin' (Gurteen 1999).

For example, there are company wikis and discussion forums at Nielsen. However, not all employees are aware that these tools exist and, therefore, they do not contribute through these channels. This means that they miss finding solutions to problems and possibly supplying solutions to the problems that other employees have. This level of ignorance about social media tools is a barrier to sharing knowledge and improving business performance.

Nielsen must embrace the use of social media tools in their effort to create a knowledge-sharing culture. However, there also has to be buy-in from all the employees that the company expects to use these tools to share their knowledge:

In a highly competitive business environment, a firm's ability to develop new products, services and processes better than its competitors depends on how effective knowledge sharing practices are established and spread among employees. (Almahamid, Awwas \& McAdams 2010:n.p.)

The crux of a knowledge-sharing culture lies with the employees, who need to interact and communicate with one another in order to share their tacit knowledge. Kang, Chen, Ko and Fang (2010) state that 'driven by a knowledge economy, many organisations have recognised knowledge as a valuable intangible resource that holds the key to competitive advantage'.

This article aimed to highlight social media trends in the effective sharing of knowledge between the employees of the Television Audience Measurement Department of the Nielsen Company.

\section{Research methodology}

The purpose of this study was to investigate social media technology trends in the Nielsen Company and to establish how these technologies can help it to create a knowledgesharing culture. The article will highlight which social media technologies the Nielsen's Television Measurement Department is currently using and will make suggestions about which tools it could incorporate to cultivate a knowledge-sharing culture in the company.

The researchers used evaluative research. Therefore, the research design was empirical, numeric and used textual data. Based on this, one can argue that the researchers drew the results from hybrid data with medium control: 'The preparation of such a design facilitates research to be as efficient as possible yielding maximal information' (Kumar 2008:14).

The choice of a qualitative methodological research design meant that the researchers could increase validity through triangulation. Triangulation increased their chances to control and assess certain threats that could have influenced the results. The research question and the field participants were the reasons for the decision to use triangulation in the research. The researchers used a qualitative design 'to test the conjecture; and when the phenomenon was measured, further qualitative descriptions were developed from the numerical results' (Morse, Niehaus, Wolfe \& Wilkins 2006).

Questionnaires are part of qualitative research methods. They allow:

the correct choice of appropriate methods and theories, the recognition and analysis of different perspectives, the reflections on the research as part of the process of knowledge production; and the variety of approaches and methods. (Flick 2009:n.p.)

Therefore, the researchers used semi-structured questionnaires that included both closed and open-ended questions as the data collection instruments. They included descriptive questions because the aim was to gather in-depth descriptions of, and perceptions about, social media tools as useful media for creating a knowledge-sharing culture at Nielsen.

The researchers completed the data analysis process, through which they derived the research findings, after collecting the completed questionnaires. They gathered additional data and insight on certain topics as engagement with groups of employees emerged whilst they were completing the questionnaires. 
The Nielsen Television Audience Measurement Department consists of approximately 50 people. The researchers received 32 completed questionnaires from the 40 that they handed out. The 32 completed questionnaires were sufficient to represent the entire department as the researchers calculated the response rate $(n)$ as $80 \%$.

The sampling method that the researchers used in this study was purposive sampling. This enabled the researchers to:

- investigate which social media technologies Nielsen's Television Audience Measurement Department was using at the time of the study

- identify other forms of knowledge sharing that Nielsen was practising

- determine which social media technologies Nielsen was using to facilitate knowledge sharing.

The purposive sampling method allowed the researchers to answer the research problem, which was to establish the extent of the use of social media technologies to enable or improve knowledge sharing in Nielsen.

\section{Research results}

The researchers conducted statistical and descriptive analyses because they kept their data analysis techniques in mind before developing the questionnaires. It is for these reasons that they asked closed as well as open-ended questions throughout the questionnaire.

A discussion of the results will follow the answers the respondents gave to the questions in the questionnaire that follow:

- What types of Social Media tools were used by Nielsen?

- What medium of communication did employees prefer (whether it is face-to-face or electronic communication)?

- Whether employees were willing to share their knowledge with others.

- What employees preferred as communication medium when they had a problem or question that needed to be answered.

- Did colleagues help one another in problem solving?

- Whether the employees within Nielsen believed that Social Media could create a knowledge-sharing culture.

\section{The types of social media tools Nielsen employees used}

Figure 1 presents the social media tools that Nielsen employees used. Skype was by far the most common tool they used. Employees used Skype to communicate with employees at the South African branch, where the researchers conducted the study, as well as to communicate with employees who worked in international branches. It was clear that Nielsen regarded Skype as an important business tool because Nielsen used it for different purposes, including daily interaction with international colleagues.

Managers used Skype for international conference calls. It allowed them to communicate with employees around the world on a daily basis. This was a textbook example of the 'new' way of doing business: 'Blogs, microblogs (e.g. Twitter) and instant messaging tools (e.g. Skype) have provided new communication tools to interact more effectively with others in opened communities' (Razmerita, Kirchner \& Sudzina 2009).

Communicating regularly is crucial for Nielsen, as it is for many other companies, because Nielsen deals with many data that need to be up-to-date and available on demand. Employees also used 'Office Communicator' every day because it is an easy tool for employees to use to communicate and collaborate with each another, especially if they work in different departments or in other globally positioned locations. Office Communicator is similar to Skype because it allows people to chat using instant messaging (IM), make personal computer (PC)-to-PC phone and video calls, share files and manage information other colleagues can see.

The interesting aspect of Figure 1 is that Nielsen had many of the common social media tools, like blogs, wikis and collaboration sites. However, employees were not using these tools to their maximum capability and potential. For example, if Nielsen connected and grouped their blogs to their international branches, they could create a knowledgesharing culture between employees and managers. This would reduce the re-creation of knowledge and employees could record valuable information for current and future use. Respondents stated that they either did not know that the social media tools existed at Nielsen or that they knew about the social media tools but they did not see them as tools that would help them in their day-to-day activities.

Other ways of sharing information or knowledge that the researchers identified through the survey were email, the Nielsen intranet (local area network), face-to-face meetings or discussions, telephone conversations, training, communication boards and 'Windows Live Messenger'. Ninety per cent of the respondents indicated that email was their preferred method of sharing knowledge, other than the social media tools.

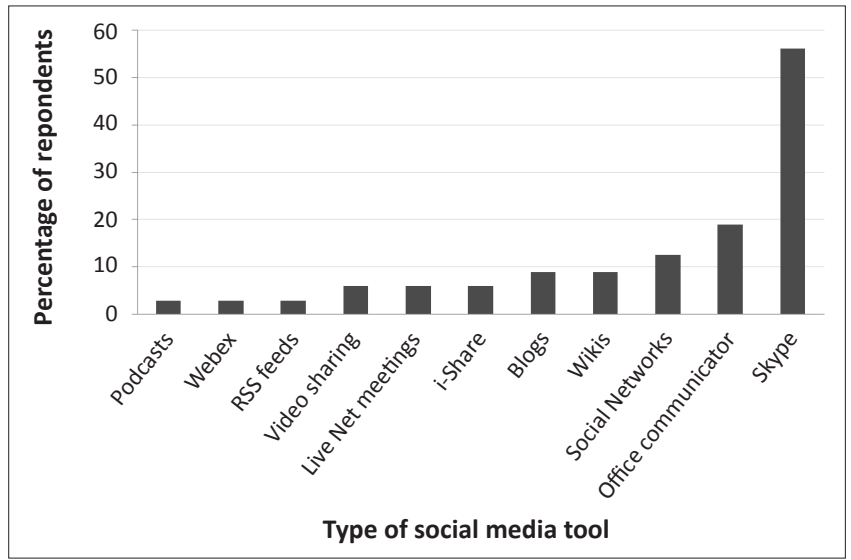

Source: Authors' own data

FIGURE 1: Social media tools that Nielsen employees used. 
These results emphasise that technology plays a major role in the communication processes that occur daily at Nielsen. It is clear that Nielsen employees use technology every day and that a concerted effort to encourage the optimal use of social media tools could benefit the company even more.

\section{The preferred modes of communication}

Figure 2 shows whether employees preferred electronic or face-to-face communication. Most respondents (66\%) preferred electronic communication to face-to-face communication because they said that electronic communication was faster, more convenient and employees could store the information for use at a later stage. Skype is one example of a social media tool that can store information after conversations. Employees can also have live meetings or conference calls and are able to see each other with the use of webcams.

Through Skype, employees can talk 'face-to-face' with international colleagues and they can use usual chat - where employees type conversations in an IM way - if they desire. Employees can view the information that contacts shared via Skype over a period of three months and they can record this information for future use if they need to.

The reasons that employees preferred electronic communication to face-to-face communication were:

- that Nielsen is a global company and face-to-face communication is not always possible

- electronic communication makes it easier and faster to communicate with international employees and to get the information that employees need faster

- employees can record electronic communication for future use and can keep information that they have sent

- electronic communication allows geographically dispersed groups to communicate interactively and simultaneously through text, sound and video

- conference calls are cost-effective

- electronic tools are easy to use and communication is transferred and received no matter where the person may be

- electronic communication is more convenient.

The positive attitude about electronic communication is also evident in these direct quotes from the questionnaires:

- 'It lets you combine numerous texts into a single message.'

- 'I can do so in my office with other reports and processes running.'

- 'You get to see the people you are communicating with and it is easier.'

- 'I can save what has been discussed or shared'.

With regard to face-to-face communication, $31 \%$ of the respondents stated that it is easier to grasp or understand something when communicating with the person in person. They saw electronic communication as impersonal and 'it can easily be misunderstood'. This is true because people do not get to see the emotions and reactions of others when they communicate using electronic tools and they may not resolve issues that may arise because misunderstandings could occur.

Although only $31 \%$ of the respondents regarded faceface communication as important, it remains an important means of communication because employees are able to walk to another's office in seconds to find a solution to their problems. However, when this type of close contact is not possible, it is crucial for employees to acknowledge the advantages of technology for quick interaction and that they can use it wherever possible because it is easier to record this communication and the resulting information and knowledge if they do so in an electronic format.

Electronic communication is revolutionising business communication. Organisations can transform passive employees into active participants because they can contribute to content, add or change content and share content. Wasko and Faraj (2005) state, 'In electronic networks, individuals contribute knowledge and help others despite the lack of a personal, face-to-face relationship'. Nielsen provides these communication tools. However, the problem is that employees resist using these tools or are unaware that the tools are available.

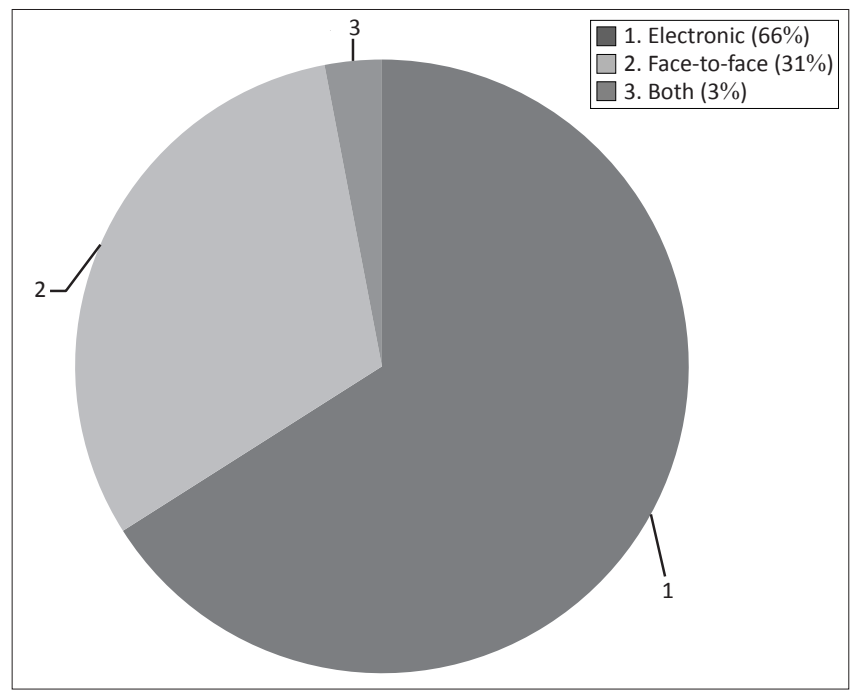

Source: Authors' own data

FIGURE 2: Preferred mode of communication.

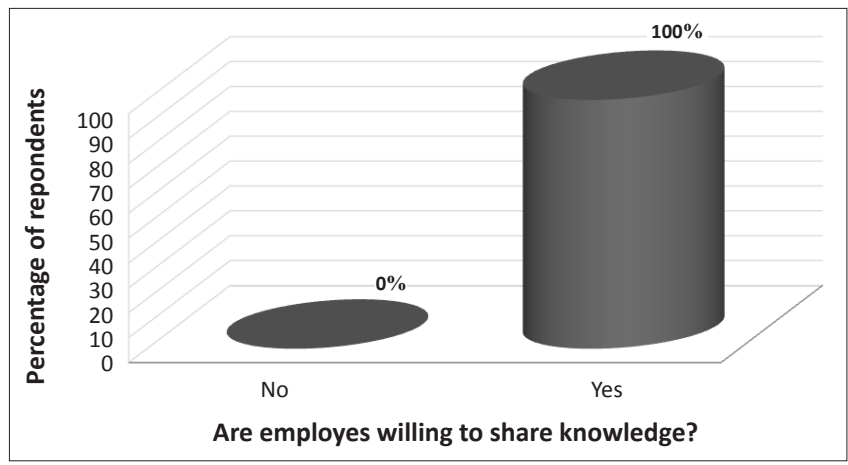

Source: Authors' own data

FIGURE 3: Employees' willingness to share knowledge. 


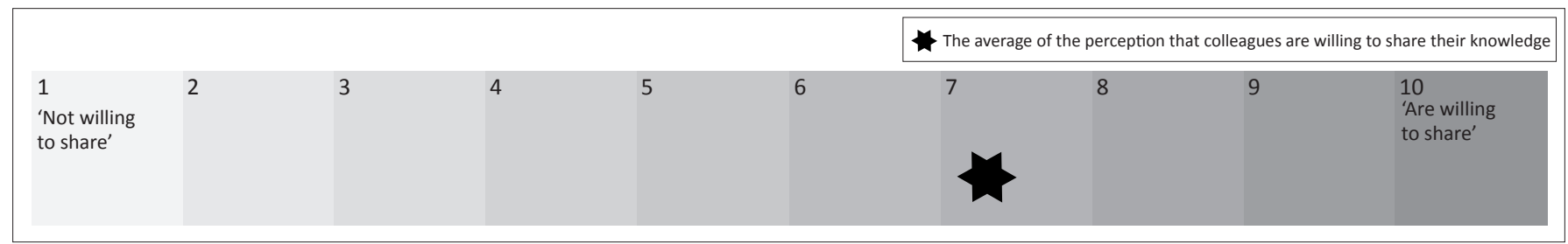

Source: Authors' own data

FIGURE 4: To what extent are your colleagues willing to share their knowledge?

\section{The willingness of employees to share their knowledge}

Nielsen managers do not have a problem with employees who do not want to share their knowledge because 100\% of respondents stated that they were willing to share their knowledge with colleagues. Therefore, the problem is not that Nielsen employees are unwilling to share their knowledge. Instead, they are just not aware of the electronic tools available to them or they are unconvinced that these tools could help them to share their knowledge effectively. Figure 3 shows whether employees were willing to share their knowledge or if knowledge sharing was absent at Nielsen. All respondents stated that they were willing to share their knowledge and that they observed the same from their colleagues.

Employees at Nielsen are willing to share their organisational knowledge because their culture is open and vibrant and employees believe in helping one another. The researchers observed the employees in the Television Audience Measurement Department throughout the day of the interviews and employees needed to confirm certain processes from time to time. When these needs arose, employees would walk to a manager's office and resolve whatever was causing them uncertainty.

Managers were always willing to help and the environment was friendly. This encouraged employees to communicate with one another as well as with their managers. The department was organised so that two to three employees worked in a spacious cubicle where they were close to each another. This made it easier to communicate and assist one another.

The Television and Audience Measurement Department offices had an arrangement so that employees could walk to another's office or cubicle if they had a problem. Sometimes this was not possible. An example is if the person they needed to answer a question was out of the office. In these cases, the employees who wanted to ask the question would use email or Skype to contact the other person.

The researchers posed the question that follows to the respondents: 'In your experience, to what extent are colleagues willing to freely share their knowledge and information with others?'. The researcher recorded the responses using a Likert scale where 1 denoted 'not willing to share' and 10 denoted 'are willing to share'.
The results averaged 7 on the Likert scale. This showed that not all employees were willing to share their knowledge, but that most employees were willing to share their knowledge and experiences with other people (see Figure 4).

\section{Preferred modes of communication when asking questions}

One should note that only 31 of the 32 respondents answered this particular question. Figure 5 below gives the statistics of the medium of communication employees preferred to use when they had a problem or question to which they needed an answer.

Respondents preferred walking to another's office when they had a question or problem, with $45 \%$ of the respondents indicating this as the preferred method of communication in such a case. The second most preferred method of communication when posing a question was a blog, wiki or Skype, as $32 \%$ of the respondents preferred this medium. The researchers established that employees regarded blogs, wikis or Skype as the most time conserving options because they could post the question and continue to work whilst waiting for a reply. 'The question can be addressed in real time, but without having to walk to the person's office'.

The $23 \%$ of respondents who preferred to email their questions did so because the information they received from the email would be in writing as 'proof' in case future disputes arose.

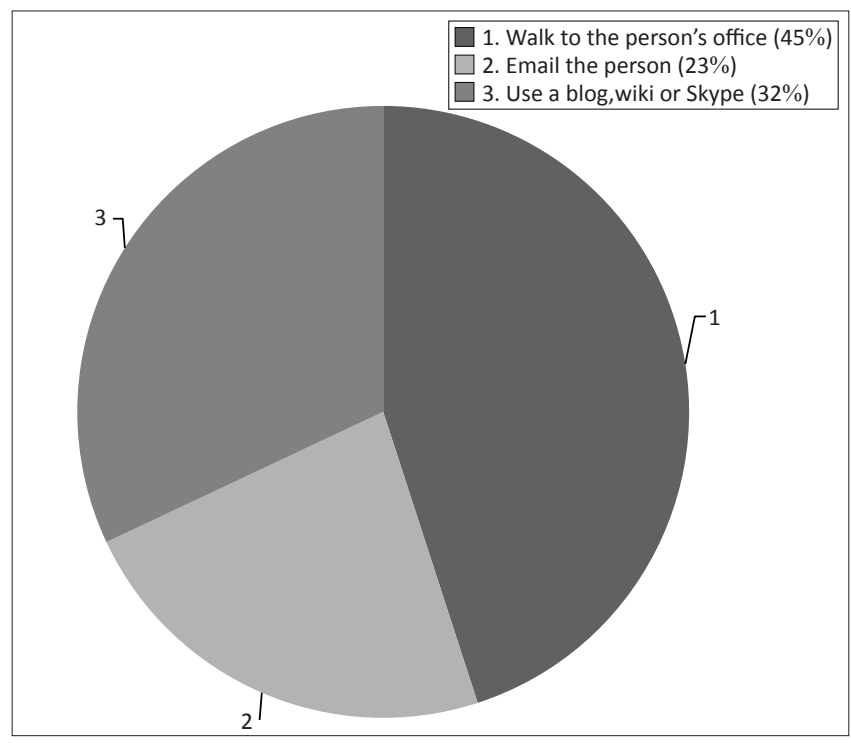

Source: Authors' own data

FIGURE 5: Employees' preferred medium when they have a question or problem. 
Other reasons for preferring email, as an option, was that it was fast and saved time.

\section{The willingness of colleagues to help each another to solve problems}

Figure 6 below illustrates that colleagues were indeed willing to assist each another to solve problems, with $72 \%$ of respondents indicating that colleagues do help each another. None of the respondents indicated that they were not willing to assist colleagues to solve problems. The $28 \%$ of respondents who indicated that they are only 'sometimes' willing to help colleagues stated that this was because they did not have answers and had to refer colleagues to someone else for help.

It was clear that Nielsen's employees were open to communication and willing to assist each another wherever they could. This is extremely important for establishing a knowledge-sharing culture because 'most researchers and practitioners agree that a major part of knowledge in an organisation is in tacit form' (Suppiah \& Sandhu 2011). Knowledge resides in the minds of employees and they can only share it in writing or through face-to-face or electronic interaction. From engaged discussions, the researchers established that most Nielsen employees were open with one another about their tacit knowledge and that they would assist others wherever possible.

\section{Employee perceptions of the contribution of the social media towards building a knowledge- sharing culture}

In its conclusion, the questionnaire asked respondents whether they thought that creating a knowledge-sharing culture, by using social media tools, would benefit Nielsen. Figure 7 gives the results.

Most respondents (94\%) answered 'yes' to this question. This confirms that most employees thought that incorporating social media tools would improve Nielsen's knowledgesharing culture. Therefore, its managers should encourage and participate in social media technologies because it is clear that there will be buy-in from employees. One expects this positive response towards the social media because, according to Dawson (2009):

[Social Media] is deeply changing the expectations of knowledge workers as to how they can build their own personal brand within a corporation, not just find knowledge they need or socialize. (n.p.)

The $6 \%$ of the respondents who answered 'no' to this question were the employees who do not agree that the social media would help to create a knowledge-sharing culture because they still believe that face-to-face communication is the most effective mode of communication and that technology should not change the 'old ways' that worked well. The organisation could persuade those who do not agree that technology could encourage sharing knowledge at least to try these technologies for themselves if the managers provided incentives to the people who contribute through social media tools.

\section{Conclusion}

This article investigated social media technology trends within the Nielsen Company and established how these technologies could help the company create a knowledgesharing culture.

The study established that the Nielsen Company has incorporated specific social media tools and technologies. However, employees do not necessarily use them optimally. Nielsen does have elements of a knowledge-sharing culture because employees are willing to share their knowledge with others by using various modes of communication. Therefore, there is knowledge sharing at Nielsen and social media tools are available to employees, but Nielsen has not yet fully realised the potential for sharing knowledge using social media tools. In order to fill this gap, integrating social media tools into the daily work processes and tasks of employees will help to solve the problem because employees will collaborate and communicate by regularly using these tools. This will lead to the habitual sharing of knowledge through social media tools.

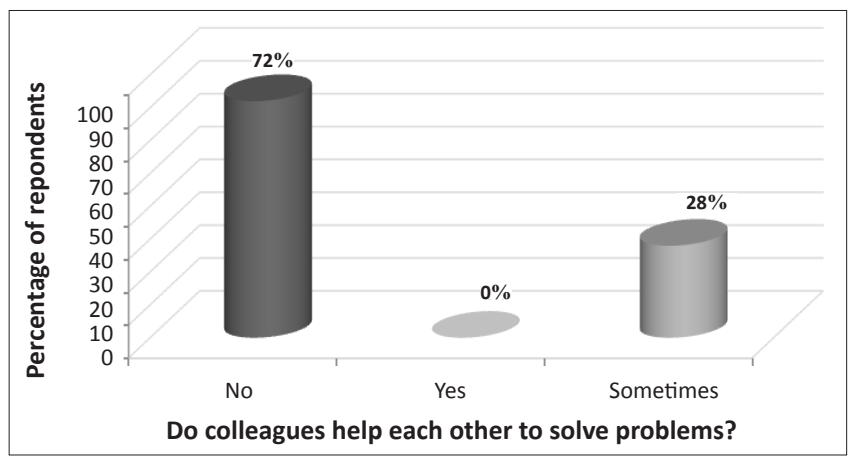

Source: Authors' own data

FIGURE 6: Colleagues who help each another to solve problems.

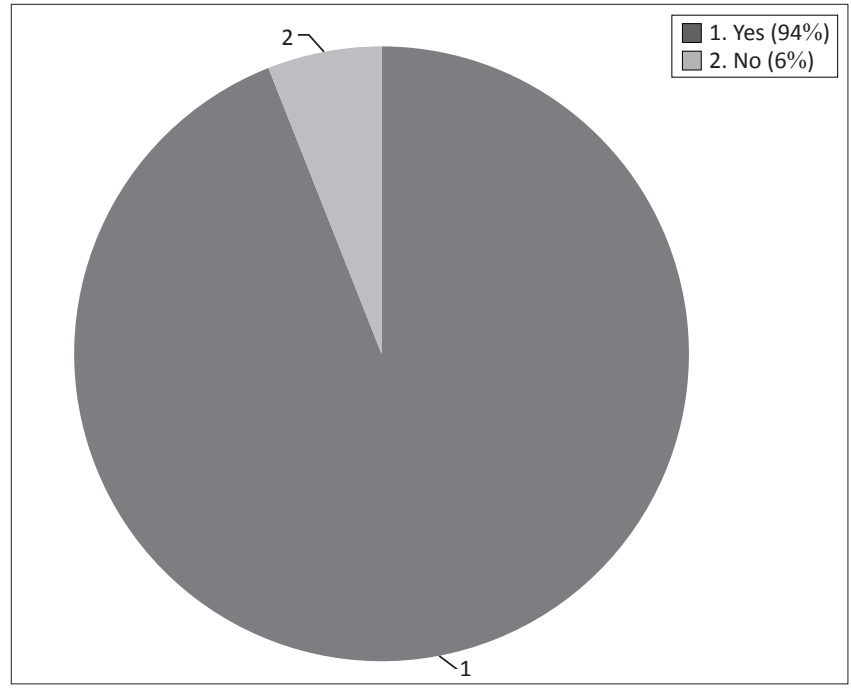

Source: Authors' own data

FIGURE 7: Perceived possibility of whether the social media can create a knowledge-sharing culture. 
This study focused on only one department at Nielsen. Therefore, the researchers do not know whether the willingness to share knowledge prevails throughout the organisation. It is an area for further research.

Further investigation into the most effective social media tools that Nielsen could use in the rest of the organisation is possible. Researchers could compare the data from follow-up studies with the data from this study and they could draw further conclusions and make suggestions. Such research could help other organisations who are hoping to establish knowledge-sharing cultures through using social media tools: 'From a managerial perspective, it is timely for research on knowledge sharing to pay more attention to the link between knowledge sharing and organisational performance' (Foss, Husted \& Michailova 2010).

Sharing knowledge is a crucial business objective. Therefore, it is important for Nielsen to tap into the intellectual capital of its employees to create competitive advantage through creativity and unique ideas.

International research concludes that companies that have embraced the social media continue to report that they are receiving measurable business benefits. Ninety per cent of these companies report at least one benefit to their business. 'These benefits ranged from more effective marketing to faster access to knowledge' (Bughin \& Chui 2011).

\section{Acknowledgements Competing interests}

The authors declare that they have no financial or personal relationship(s) that may have inappropriately influenced them when they wrote this paper.

\section{Authors' contributions}

D.A. (University of Johannesburg) completed this research as part of the Information Management Honours degree module of 'Research Methodology'. M.M. (University of Johannesburg) was the Research Methodology lecturer and provided guidance for the research design and execution of the empirical process. A.P. (University of Johannesburg) compiled the final article for this publication.

\section{References}

Almahamid, S., Awwad, A. \& McAdams, A.C., 2010, 'Effects of Organisational Agility and Knowledge Sharing on Competitive Advantage: An Empirical Study in Jordan', International Journal of Management 27(3), 387-388.

Bughin, J. \& Chui, M., 2011, 'McKinsey on business technology: the rise of the networked enterprise; Web 2.0 finds its payday', McKinsey quarterly, Spring 2011 viewed 06 September 2011, from www.mckinseyquarterly.com

Dawson, R., 2009, Implementing Enterprise 2.0: A practical guide to creating business value inside organisations with web technologies, Advanced Human Technologies, value inside
London.

Flick, U., 2009, An introduction to qualitative research, SAGE Publications, London.

Foss, N.J., Husted, K. \& Michailova, S., 2010, 'Governing knowledge sharing in organizations: levels of analysis, governance mechanisms and research directions', Journal of Management Studies 47(3), 455-482. http://dx.doi.org/10.1111/ j.1467-6486.2009.00870.x

Gaffoor, S. \& Cloete, F., 2010, 'Knowledge Management in local Government: the case of Stellenbosch Municipality', South African Journal of Information Management 12(1), 1-2.

Gurteen, D., 1999, 'Creating a Knowledge Sharing Culture', Knowledge Management Magazine 2(5), 1-2.

Herrick, A., 2011, Insights 2012: How Digital Innovation Impacts Your Business, viewed 06 September 2011, from http://www.sapient.com/assets/ Imagedownloader/1061/Insights2012.pdf

Jones, B., Temperley, J. \& Lima, A., 2009, 'Corporate reputation in the era of Web 2.0: the case of Primark', Journal of Marketing Management 25(9), 936. http://dx.doi. org/10.1362/026725709X479309

Kang, Y.C., Chen, G.L., Ko, C.T. \& Fang, C.H., 2010, 'The exploratory study of online Knowledge Sharing by applying wiki collaboration system', Scientific Research 2(1), 243-244

Kumar, R., 2008, Research Methodology, APH Publishing Corporation, New Delhi.

Longo, M. \& Mura, M., 2011, 'The effect of intellectual capital on employees satisfaction and retention', Information \& Management 48(2011), 278-287. http://dx.doi.org/10.1016/j.im.2011.06.005

Morse, J.M., Niehaus, L., Wolfe, R.L. \& Wilkins, S., 2006, 'The role of the theoretical drive in maintaining validity in mixed-method research', Qualitative Research in Psychology, 3(4), 290-291.

Punch, K.F., 2005, Introduction to social research: qualitative and quantitative approaches, SAGE Publication, London.

Razmerita, L., Kirchner, K. \& Sudzina, R., 2009, 'The role of Web 2.0 tools for managing knowledge at individual and organisational levels', Online Information Review 33(6), 1022-1023. http://dx.doi.org/10.1108/14684520911010981

Suppiah, V. \& Sandhu, M.S., 2011, 'Organisational cultures influence on tacit knowledge - sharing behaviour', Journal of Knowledge Management 15(3), 464.

Wasko, M.M. \& Faraj, S., 2005, 'Why should I share?', MIS Quarterly 29(1), 35-57. 